\title{
Responses of Diabetes Mellitus Patients Who Used Complementary Medicine
}

\author{
Anita Joeliantina ${ }^{1,2}$, Mangestuti Agil ${ }^{3}$, M. Bagus Qomaruddin ${ }^{4}$, Arijanto Jonosewojo ${ }^{5}$, Kusnanto ${ }^{6}$ \\ ${ }^{1}$ Department of Nursing, Health Polytechnic Ministry of Health Surabaya, Indonesia \\ ${ }^{2}$ Doctoral Program in Health Science, Faculty of Public Health, Airlangga University, Indonesia \\ ${ }^{3}$ Faculty of Pharmacy, Airlangga University, Indonesia \\ ${ }^{4}$ Faculty of Public Health, Airlangga University, Indonesia \\ ${ }^{5}$ Faculty of Medicine, Airlangga University, Indonesia \\ ${ }^{6}$ Faculty of Nursing, Airlangga University, Indonesia
}

\section{Article Info}

Article history:

Received Sep 10, 2016

Revised Nov 20, 2016

Accepted Nov 26, 2016

\section{Keyword:}

Complementary medicine

Alternative medicine

Diabetes mellitus

\begin{abstract}
Diabetes Mellitus as a chronic disease tend to seek appropriate medical treatment to heal the condition. Health-seek searched can be either medical treatment or Complementary and Alternative Medicine. This study explored deeply on the response of diabetes mellituspatients who visited to Indonesian Traditional Medicine Polyclinic on Regional Public Hospital dr. Soetomo Surabaya in using complementary medicine. This study used qualitative study with phenomenological method approach. The focus of this study was diabetes mellitus patients who use complementary medicine. Nine participants were selected based on purposive sampling method with certain criteria. Data collection used was in-depth interview and field note. Data analysis used thematic content analysis. Determining five themes that correspond with the purpose of study and a new theme. Some themes were psychological response after being diagnosed diabetes mellitus, opinion on the diabetes mellitus disease, complementary medicine usage patterns, reasons, the response after the use of complementary medicine, and family support. As a chronic disease, patients need proper treatment and conduct it continuously. Healer shopping was often taken by diabetes mellituspatients. It was required cooperation between patients and health professionals to monitor the behavior in order to achieve the effectiveness of medical treatment.
\end{abstract}

Copyright @ 2016 Institute of Advanced Engineering and Science. All rights reserved.

\section{Corresponding Author:}

Anita Joeliantina,

Nursery Study on Health Ministry Polytechnic Surabaya,

Jl. Mayjen. Prof. Dr. Moestopo No. 8C, Surabaya-60115, Indonesia.

Email: anitajoeliantina@yahoo.com

\section{INTRODUCTION}

Diabetes Mellitus (DM) is a group of metabolic diseases characterized by hyperglycemia resulting from defects in insulin secretion, insulin action, or both [1-2]. Long-term complications of diabetes include dysfunction of heart and blood vessels, nephropathy, retinopathy and neuropathy [1]. According to data published in the Diabetes Care 2004journal, DM patients in Indonesia in year 2000 reached 8.4 million people and ranked fourth after India, China and United States. The number was estimated to increase more than twice in 2030, to 21.3 million people [2-3]. According to the Health Study Association 2013, the prevalence of DM patients in Indonesia increased $1.1 \%$ in 2007 to $2.1 \%$ in 2013 [4]. Number of DM patients type 2 (DMT2) was estimated to reach $90 \%-95 \%$ of DM patients, compared to DM patients type 1 (DMT1) who only amounted $5 \%-10 \%[1]$. 
Complementary and Alternative Medicine (CAM) is a group of diverse medical and health care systems, therapies, and products that are not presently considered to be part of conventional medicine. CAM is categorized as complementary, alternative, and integrative, depending on how an individual uses the CAM. If an individual used CAM combined with conventional medical treatment, he would use complementary medicine. If an individual usedonly CAM without any conventional medical treatment, he would use alternative medicine. If an individual systematically or intentionally combined CAM with conventional medical treatment, he would use integrative medical treatment [5-6].

CAM is more likely to be utilized and used by people who have chronic diseases. Chronic diseasesusually require daily care and often involve some conventional pharmacological intervention. CAM can affect individual's health with chronic diseases for many therapies and treatments with CAM can be used in combination with or without conventional medical treatment for chronic diseases [7]. Treatment for diabetes as a chronic disease is continously conducted, mainly by maintaining glucose levels within normal tolerance. Although there is conventional therapy sometimes it still causes complications. Therefore, medicine development is continuosly conducted i.e by using herbal medicine as an alternative or complementary medicine. CAM that is widely used by diabetes patients are herbal, vitamin, and prayer. In the US, CAM that most widely used by patients with diabetes were herbal, supplements (vitamins and minerals), mind body therapies [8].

Health-seeking behaviour as indicated by diabetes patient was a hierarchy that started from self-treatment, then lead to medical treatment or conventional medicine. Sources of treatment include three interrelated sectors, family / self-treatment, conventional treatment, and professional medical treatment. The selected treatment can be combining utilized, like medical and conventional treatment [9]. According to Kroeger (1983) health-seeking behaviour was known as a healer shopping which will be utilized by patients to deal with complaints of illness. Health-seeking behaviour was influenced by many things, one of which was the status of the patients' disease: acute or chronic. Patients with chronic diseases tend to seek treatment more than one [10-11].

There was a tendency that emerged around the world for DMT2 patients to use or select CAM in order to increase their health status. The prevalence of CAM used in the US showed consistent high percentage at $72.8 \%$ in 2006 and $86.6 \%$ in 2010 [12-13]. Likewise in Malaysia, the prevalence of DM patients who used CAM in 2011 was $49.60 \%$, and an increased to $62.50 \%$ in 2013 [14-15].

Complementary and Alternative Medicine in Indonesia has been regulated in the Health Minister Regulation of Indonesia Republic, Number 1109 / MENKES / PER / IX / 2007 on Implementation of Complementary and Alternative Medicine in Health Care Facilities. Complementary medicine today has been applied to the health services in Surabaya which already have traditional medicine services at 20 community health centers in Surabaya and Regional Public Health dr. Soetomo Surabaya. According to dr. Esti Martiana (2011), people who took medical treatment in community health centers would have two treatment options. The selection could be a medicine from the doctor or traditional medicine. Traditional medicine services in the community health centers in Surabaya included acupuncture, acupressure, baby massage, as well as herbal consultation.

Regional Public Health Dr. Soetomo Surabaya also provided traditional medicine services in Indonesian Traditional Medicine Polyclinic (Poliklinik Obat Tradisional Indonesia = OTI), which aimed to meet the needs of public health services. Health services consisted of herbal therapy, acupuncture and massage aromatherapy. It was similar with other conventional polyclinics, Indonesia Traditional Medicine Polyclinic also delivering levels of services including promotive, preventive, curative, rehabilitative and palliative. DMT2 patients also utilized traditional health services at Indonesian Traditional Medicine Polyclinic. In 2014 the number of DMT2 patients who visited to Indonesian Traditional Medicine Polyclinic reached 50 people.

The purpose of this study was to explore in depth about the responses of DM patients who visited to Indonesian Traditional Medicine Polyclinic in Regional Public Health Dr. Soetomo Surabaya in using complementary medicine. The behaviour of complementary medicine usage explored into five themes, namely: psychological responses after diagnosed DM, opinions about the disease, complementary medicine usage patterns, the reason for using complementary medicine, and the response to the treatment.

\section{RESEARCH METHOD}

This study used qualitative design with phenomenological method approach, with the focus on DM patients who use complementary medicine. Nine participants were selected based on purposive sampling with the criteria using complementary medicine at least 3 months, suffered from DM for more than one year, and the patient's age ranged between 30-65 years old. This study was conducted at Indonesian Traditional Medicine Polyclinic in Regional Public Health dr. Soetomo Surabaya in August and October 2015. Data 
collection employed indepth interview and field note. All participants had preliminary explanation about the study, the procedures and the rights of participants by signing inform consent. Data analysis used thematic content analysis. This study had through ethics test by ethics study committees of Regional Public Health dr. Soetomo Surabaya as noted Number 449 / Panke. KKE / IX / 2015.

Validation was data using communicative validity to confirm the data that has been obtained, and descriptions to the research subjects. Another validation is done by triangulation techniques through a family member of a participant (husband or child), the experience of researchers in the field of medical surgical nursing and Transcultural nursing, especially in health care patients with diabetes mellitus, and associate with literature review.

\section{RESULTS AND ANALYSIS}

This study did not explain about the reason of why participants select to get medical treatment in Indonesian Traditional Medicine Polyclinic, but more emphasized on the reason of why participants used the complementary medicine. Indonesian Traditional Medicine Polyclinic was only used as tool to determine participants who were using or selecting herbal medicine, both recommended by Indonesian Traditional Medicine Polyclinic and also outside Indonesian Traditional Medicine Polyclinic. Herbal medicines recommended by Indonesian Traditional Medicine Polyclinic were paniculata capsule, bayleaf capsule, the combinationof both and altilis leaf capsule. Herbal medicine used by participants who were not visited Indonesian Traditional Medicine Polyclinic were bayleaf, cinnamon, paniculata, TF supplements, and ruellia tuberosa leaf.

The number of participant in this study were 9 people, where 3 people undergoing treatment in Indonesian Traditional Medicine Polyclinic and while 6 people remaining had experience in taking medical treatment in the Indonesian Traditional Medicine Polyclinic in 2016. All participants acknowledged that they were suffered from diabetes from the doctor's diagnosed. Five participants stated that they visited doctor for a health check due to some health complaints hand numbness, limp, thin, have frequent urinate, and sleepy. One participant deliberately checked out because of the possibility suffering from diabetes due to inheritance. Three participants diagnosed diabetes by doctor during health control for other diseases (hypertension, cholesterol) and result of laboratory's blood checking during treatment in health facilities which indicate an increase in glucose.

Characteristics of participants showed in this study divided into individual characteristics and disease characteristics. The individual characteristics included gender, age, and education. All the participants were female. The age of participants ranged between 45-65 years old, with the distribution of 4 participants aged around 45-50 years old, 3 participants aged 51-55 years old, and 2 participants aged around 61-65 years old. Data on participants' education was one participant did not complete elementary school, 7 participants graduated from high school (or equivalent), and 1 participant graduated from university (Bachelor Degree).

Diseases characteristics included the type of diseases, period of illness and period in using complementary medicine. All participants were diagnosed diabetes mellitus type 2 and have suffered more than one year, with the category of 1-5 years as many as 6 people and 6-10 years as many as 3 people. While the period in using complementary medicine was more than 3 months, with the category of 3-12 months as many as 4 people, 1-5 years as many as 4 people, and more than 5 years as many as 1 people.

The results of in-depth interview with participants, obtained five themes on psychological responsesafter diagnosed DM. The themes were psychological responses after diagnosed DM, opinions about DM, medical treatment selection pattern, the reasons to select complementary medicine, responses to complementary medicine, and family support for the use of complementary medicine. Below the quot answers of the participants:

\subsection{Psychological Responses after Diagnosed DM}

DM is a chronic disease that will be suffered a lifetime. Someone who had a chronic disease always difficult to accept the fact that they have to change their lifestyle [16]. Patients who have received a diagnosis of diabetes can make them into a loss of control [17]. They must adhere and adapt with new different routines, like getting injections of insulin, consume healthy food and do physical exercise. Stress on DM patientscaused by assortment pressure to live normally. Patients should be able to integrate the DM pressure into daily routinity. Chronic disease resulted senses of loss, such as adding financial difficulties for most individuals and bringing changed in lifestyle and dependence on others [18]. Stress has three forms, namely: stimulus, response, and process. Response is individual reactions that arise because of certain situations that cause stress. Response that arises can be physiological, such as: palpitations, trembling, dizziness, and 
psychological responses such as fear, anxiety, difficult toconcentrate, and easily irritated. Participants in this study showed responses to the stress, mainly psychological responses.

Psychological response showed by 9 participants in this study wasfear response, as expressed by 3 participants: “... I was scared when they said I got diabetes ... ", downresponse expressed by 2 participants: "I was down at first, limp.... that I got diabetes ... ", anxiety response expressed by 1 participant:"I feel anxiety when they said $i$ got diabetes ...", confused response expressed by 1 participant:"I am so confused ...". One participant showednormal psychological response against diabetes diagnosis given by the doctor. Two participants showed their rejection response after diagnosed DM. The responses could be seen from the participant expression:"... I don't believe that I'm diagnosed diabetes, how could it be". The reaction of this denial in accordance with the theory of loss by Kubler Rose, the first reaction of individuals who experience loss is shock, disbelief, or to deny the fact that the loss actually occurs. DM patients experience a loss of physiology related to loss of adequate pancreatic function, which function in the pancreas secrete the hormone insulin needed to regulate blood glucose levels.

Although initially, 8 of 9 participants showed psychological responsesas fear, anxiety, confuse, down, and rejection, but in the end they could accept the fact. The expression of reception was showed:"... Finally I accept it, as it is ...". In the acceptance stage, participants sense of loss in life and find a way to move forward. The acceptance phase is related to the reorganization of the feeling of loss, thoughts were always centered on the missing objects begin to diminish or disappear. Individuals have to accept the fact that experienced loss and start to look forward.

\subsection{Opinions about DM}

Opinions of DM patients were explored in this study associated with risk factors that could cause DMT2. Some risk factors could affect DM morbidity. The risks consisted of genetic and lifestyle such as diet and activity patterns. The lifestyle was a factor that could be changed with a good self-management [2], [19]. DMT2 is a chronic disease that requires routine health management and sustainable thus needs proper medical treatment [20].

DM patients who visited Indonesian Traditional Medicine Polyclinic comprehend about DM disease as inherit disease, even among them not found any history of heredity, unhealthy lifestyle, uncontrolled eating, lack of exercise, and less activity. In addition there were participants who said that DM is a disease that incurable and must take medicine in whole life. Below were statements from participants about DM:

1. DM is inherited: "DM is known to be inherited ...",

2. Unhealthy lifestyle as a reason: “... as uncontrolled eating, lack of exercise, and various causes",

3. DM disease must take medicine for whole life and incurable, as expressed: "Diabetes will need medication for whole life and incurable, so yes, I'm afraid".

All participants expressed their opinions on the risk factors of DM because they had suffered from it for more than one year and got enough information from health professionals.

\subsection{Complementary Medicine Usage Pattern}

The health-seeking pattern behaviour showed hierarchy started from self-treatment, seek for medical treatment and other treatments (complementary and alternative or traditional) [9]. In accordance with the theory of healer shopping developed by Kroeger (1983), during the illness, the patient was likely to seek a second healer, without reference from the first. Likewise, DMT2 patients had a tendency to do complementary medicine to increase their health status [14-15], [21].

This study explored the pattern of treatment selected by DM patients. CAM usage pattern was behaviour tendency showed by diabetes patients in using CAM as a complement to conventional treatment being undertaken. In this literature study, the pattern of CAM usage showed by diabetes patients were, (1) mostly CAM used combined with conventional treatment / allopathy, (2) did not change their treatment, both in the treatment schedule or dosage, (3) reduced one dosage lower or more of conventional treatment, (4) used conventional treatments and CAM in different times, and (5) stopped the conventional treatment when using CAM [22-25].

This study results that participants have a habit in using herbal medicine before visiting Indonesian Traditional Medicine Polyclinic, still using herbal medicine eventhough no longer visiting Indonesian Traditional Medicine Polyclinic, combining medical treatment with herbal, changing the dosage of medical treatment when using herbal, not informing to doctor who handled that they used herbal more than one. Statement of participants who showed complementary medicine usage expressed as below:

1. Some participants used complementary medicine (herbal, supplements) after diagnosed DM. The pattern could be seen from their opinions: "... I also drink extracts of pace (Morinda citrofolia) after diagnosed diabetes", "... stew of bayleaf, betel and ginger ...", "... stew of cinnamon ...", "... bitter herbal (stew of paniculata), stew of leafflower ... " 
2. Some participants still used herbal eventhough no longer visiting Indonesian Traditional Medicine Polyclinic, as expressed by participant: "Right now I only consume paniculata every day ...", "drink stew of pinnata and cinnamon", "... drink bitter herbal alternately with glibenclamide ...", " ... I continue to drink ruellia tuberosa leaf ..."

3. Participant selected complementary medicine by combining medical treatment with herbal or supplements. However, some participants made changed to the medical treatment without reporting to their doctors. Changed in the treatment were by: reducing the dosage of medical treatment or did not take it, yet still consuming herbal or supplements. Statement of participants that indicated they changed the treatment as expressed: "If my glucose is normal, I do not drink metformin, will only drink bitter herbal". "... I take paniculata leaf capsule and metformin but I don't drink the metformin", "I take metformin and glibenclamide, but I don't drink metformin, while not every day consuming glibenclamide. I am switching it with bitter herbal".

The health-seeking behaviour pattern was influenced by the type and severity of symptoms, the type of disease (acute or chronic). Mainly diabetes patients who use CAM did not inform to their doctors or health professionals. The reasons of why diabetes patients of CAM users did not inform their doctor about their CAM usage as follows reasons: health professionals would prevent the use of CAM and health professionals did not have adequate knowledge about CAM. From those reasons required health policy from government on the use of CAM in health facilities [25].

\subsection{Reasons to Use Complementary Medicine}

Some reasons which became basic in taking decision to choose herbal medicine or supplements as a companion to medical treatment was assessed in this study. In-depth interviews that had been conducted on 69 participants, 42\% ( $\mathrm{n}=29)$ had identified the benefits of CAM usage for diabetes patients, some tremendous improvements in glucose which was associated with CAM. This condition considered positively affect diabetes by helping to 'prevent harm' from chronic conditions, stabilizing or lowering glucose, positive feelings that arised and saying that chronic disease was 'less of a problem' [26]. The reasons of diabetes patients using CAM with strong belief as stated that CAM is safer, have fewer side effects, CAM will maintain the health, and the use of CAM due to less effective in allopatic treatment [27]. There was also belief that CAM had synergistic effect with conventional treatment [23]. Chang et al., 2011 explained that the reason for diabetes patients using CAM was to control diabetes, heal complications, and most (71.9\%) other conditions associated with health.

Some opinions of participants related to the reasons to select complementary medicine were due to consider that medical drug contained chemicals, consider the side effects of medical treatment, and the presence of other diseases besides DM, as expressed in below statements:

1. Medical drugs contained chemicals: "I do avoid drugs, afraid to realize its chemicals contained".

2. Side effects of drugs: "I am afraid of side effects when taking medicine from doctor because it must be consumed continuously", "I am afraid of later side effects which can attack heart". "I get vomited every time drinking acarbose and glipirid medicine, so I stop it", "... if I drink metformin continuously, it will attack my kidney, I become afraid then."

3. The presence of other diseases: "I drink herbal to minimize drug consumption because I already norvask for hypertension, thus I don't want to confuse in taking medicine".

Qualitative study conducted in Hortus Medicus Herbal Saintification Clinic, showed some benefits in using herbal medicine for DMT2 patients, like to avoid treatments with chemicals contamination, have efficacy and low expenditure. Patients examined first by doctor before getting the herbal prescription [28]. All the ingredients that put into the body would have possibility to cause side effects. Similar with medical treatment, herbal medicine could cause side effects. These side effects were influenced by the dosage consumed, body condition, and combining consumption with medical treatment. The way to minimize these side effects was to determine the efficacy and dosage of herbal medicine used [29].

\subsection{Responses Towards Complementary Medicine}

The plants consumed as herbal medicine for diabetes are paniculata and bayleaf that have a hypoglycemic activity. Based on study, paniculata has benefit to prevent the absorption of glucose from intestine and increase glucose metabolism, while bayleaf has hypoglycemic effect on DMT2. Thus paniculata and bayleaf have benefit to lower glucose levels on DMT2 [30].

Participants in this study consumed various herbal. Herbal used in Indonesian Traditional Medicine Polyclinic were bayleaf capsule, paniculata, altilis leaf and combination of bayleaf and paniculata. Herbal consumed outside Indonesian Traditional Medicine Polyclinic were bayleaf, cinnamon, paniculata, Pace (Morinda citrifolia), ruellia tuberosa plants, and Africa leaf. Participant responses to complementary medicine selection were subjective on the effects caused after consumed complementary treatment. Effects 
caused by subjective statements of these participants could be physical changes perceived and glucose level checking. The statement as expressed,"If I take herbal medicine, my body feels good, my glucose lowering, my HbAlc also becomes normal"

Some herbal were safe and effective to use for many conditions. Despite the increased use of herbal products, there were no increasing reports of toxicity [18]. In choosing treatment and medicine used, either herbal or chemical, it must consider the needs, circumstances, and conditions faced. It was based on the reaction and the different work between the two types of drugs. Conventional treatments such as surgery, was more effective when using in an emergency, chronic illness, or surgery cases, because it had relatively faster effect. If in these conditions patients wanted to use herbal medicine, could still be given but must be combined with conventional medicine. Herbal medicine could be used with our without conventional medicine combining, if the patient still in normal or stabil condition. If it used with combination, then should be time interval when consuming, to achieve maximum effectiveness [29].

The result of this study was phenomenon that obtained in the field. This phenomenon needs to get the attention from health professionals so that proper management of DM can be taken by DM patients who use complementary medicine either used with or without combining it.

\subsection{Family Support Towards Complementary Medicine Usage}

Family support is the attitude, actions and acceptance of the family towards members. Family support is defined as verbal and non verbal information, advice, real support or attitude given by people who are familiar with the subject in their environment or in the form of presence and matters that can provide emotional benefits and effect on the behaviour of the recipient. In this case, people who feel they receive emotional support relieved for the attention, get advice or a pleasant impression on him / her. Family support is defined as a part of social support, is a form of interaction between individuals who provide physical and psychological comfort through fulfilment demand for affection and security. Family support has been divided into four dimensions are dimensions empathetic support, encouragement dimensions, dimensions of facilitative and participative dimensions [31].

This study showed that family support patients to use herbal medicine. Family support provided was in the form permiting to use herbal medicine, remind schedule / time to drink herbal medicine, provide information about herbal medicine, deliver to health care facilities or to buy medicine, and help to prepare herbal preparations (stew). Expressions of family support can be seen from the statement of the participants as follows:

1. Family gave permission to use herbal medicine: "I asked to my husband and he said okay", "My husband gave his permission".

2. Remind schedule / time to take medicine: "remind me whenever I should take medicine".

3. Provide information on herbal medicine: "giving information on herbal", "I am also given a brochure about herbal medicine by my husband".

4. Deliver to the health facility or buy medicine: "Sometimes my husband drive me to control in hospital", "often when I do health checking, my husband drive and accompany me", "I am reminded to control."

5. Help to prepare herbal preparations (stew): "he has even prepared it so I just need to drink it", "my husband get me bayleaf on the tree in front of our house".

It was generally believed that social support is crucial to encourage someone to have positively health behaviour and conduct effective treatment in acute and chronic diseases [32]. DMT2 is a chronic disease that requires whole life management so that patients will seek treatment he thinks can solve his complaints. There are times when patient is experiencing boredom and sense of failure in carrying out the treatment that causes patients to stop their treatment and search or choose another treatment. Family support gives effect to the patient to determine which treatment option will be taken and the implementation of selfcare. Family support is needed for people with positive attitudes toward CAM and those with high family support are more likely to use CAM and more involved in self-care behaviours [26].

\section{CONCLUSION}

Study on Complementary Medicine Selected Behaviour By DM Patients in Indonesian Traditional Medicine Polyclinic, Regional Public Hospital Dr. Soetomo Surabaya, had identified six themes, five themes that correspond with the purpose of study and one new theme through analysis process. The theme was psychological response after diagnosed DM, opinions about the disease, complementary medicine usage patterns, the reason for using complementary medicine, responses to the complementary medicine and family support for the use of complementary medicine in the new theme.

DM patients tend to use more than one treatment as an effort to solve their health problems. Selected complementary medicine was herbal medicine where it used more than one. This pattern indicated healer 
shopping in DM patients. Statement participant described as a theme in this study need to get attention from family, healthcare professionals, and governments to manage DM properly. The high interest of DM patients to use complementary medicine needs to be accomodated, so the patients' treatment always monitored.

\section{ACKNOWLEDGEMENTS}

The authors would like to thank all participants for their information and experiences that have been shared with us.

\section{REFERENCES}

[1] American Diabetes Association, "Diagnosis and Classification of Diabetes Mellitus," Diabetes Care, vol.36, 2013.

[2] Indonesian Society of Endocrinology, "Consensus Control and Prevention of Diabetes Mellitus type 2 in Indonesia," 2011.

[3] W. Sarah, et al.," Global prevalence of diabetes," Diabetes Care, vol/issue: 27(5), pp.1047-1053, 2004.

[4] Agency for Health Study and Development Ministry of Health, "Basic Health Research in 2013", 2013.

[5] A. J. Emily, "Complementary and Alternative Medicine Use among College Students: Roles of Attitude and Health Belief Model," The Graduate School University of Wisconsin-Stout, Graduate Degree/ Major, MS Applied Psychology, 2012.

[6] National Center of Complementary and Alternative Medicine (NCCAM), National Institute of Health, "Exploring the Science of Complementary and Alternative Medicine, Third Strategic Plan 2011-2015," 2011. https://nccam.nih.gov/health/integrative-health.

[7] S. H. Saydah and M. S. Eberhardt, "Use of Complementary and Alternative Medicine among Adults with Chronic Diseases: United States 2002," J Altern Complement Med, vol/issue: 12(8), pp. 805-812, 2006.

[8] B. Gurjeet S. and Y. Gloria, "Complementary and Alternative Medicine Therapies for Diabetes: A Clinical Review," Clinical Diabetes, vol/issue: 28(4), pp. 147-155, 2010.

[9] A. Kleinman, "Patiens and healers in the contex of culture," University of California Press, Barkeley Los Angeles London, 1980.

[10] A. Kroeger, "Anthropological and Socio-Medical Health Care Research in Developing Countries," Soc. Sci Med, vol/issue: 17(3), pp. 147-161, 1983.

[11] T. Tomison, "Health-seeking behaviour and strategic healthcare planning in Sierra Leone," International Development, Working paper Series, vol.13, pp. 139, 2013. ISSN 1470-2320.

[12] A. R. Bell, et al., "Complementary and Alternative Medicine Use among Adults with Diabetes in The United States," Alternative Therapies, vol/issue: 12(5), pp.16-22, 2006.

[13] V. C. Leonel, et al., "Ethnic differences in complementary and alternative medicine use among patients with diabetes," Complementary Therapies in Medicine, vol/issue: 18(6), pp. 241-248, 2010.

[14] Hassan S., et al., "Reasons, Perceived Efficacy and Factors Associated with Complementary and Alternative Medicine among Malaysian Patiens with Diabetes Mellitus," Br. J. Diabetes Vasc. Dis, vol. 11, pp. 92-98, 2011.

[15] Ching S. M., et al., "Complementary alternative medicine use among patiens with type 2 diabetes mellitus in the primary care setting: across-sectional study in Malaysia," BMC Complementary \& Alternative Medicine, vol. 13, pp. 148, 2013.

[16] K. J. Isselbacher, "Harrison's principles of internal medicine," A.H Asdie, Terj., Jakarta, EGC, vol. 5, 2000

[17] D. D. Ignatavicius and M. L. Workman, "Medical Surgical Nursing: Critical thinking forcollaborative care," Philadelphia, Elsevier Saunders, 2006.

[18] P. A. Potter and P. Anne G., "Fundamentals of Nursing," 7th edition. Canada, Elsevier Mosby, 2009.

[19] J. S. Dorman, et al., "Health Beliefs among Individuals at Increased Familial Risk for Type 2Diabetes: Implications for Prevention," Diabetes Res ClinPract, vol/issue: 96(2), pp.156 - 162, 2012

[20] Funnel M. M., et al., "National Standards for Diabetes Self-Management Education," Diabetes Care, vol/issue: 34(1), pp. S89-S96, 2011.

[21] Medagama A.B., et al., "Use of Complementary and Alternative Medicines (CAMs) Among Type 2 Diabetes Patiens in Sri Lanka: a Cross sectional Survey," BMC Complementary \& Alternative Medicine, vol. 14, pp. 374, 2014.

[22] Hashempur M. H., et al., "Complementary and alternative medicine use in Iranian patients with diabetes mellitus," Journal Integr Med, vol/issue: 13(5), pp. 319-325, 2015.

[23] Fan P. E. M., et al., "Patterns of Complementary and Alternative Medicine Use Among a Group of Patients with Type 2 Diabetes Receiving Outpatient Care in Singapore," International Journal of Nursing Practice, vol/issue: 19(3), pp. 44-55, 2013.

[24] A. Stayeh M. S., et al., "Complementary and alternative medicine use amongst Palestinian diabetic patients," Complementary Therapies in Clinical Practice, vol. 18, pp. 16-21, 2012.

[25] Chang H. A., et al., "Use of Complementary and Alternative Medicine among People with Type 2 Diabetes in Taiwan: A Cross-Sectional Survey," Evidence-Based Complementary and Alternative Medicine, vol. 2011, 2011. Article ID 983792, 8 pages doi:10.1155/2011/983792.

[26] Canaway R., et al., "Perceptions of Benefit of Complementary Therapy Use among People with Diabetes and Cardiovascular Disease," Forsch Komplementmed, vol/issue: 21(1), pp. 25-33, 2014. 
[27] Mita S., et al., "Reasons of using complementary and alternative medicine (CAM) among elderly Malaysian of Kuala Lumpur and Selangor states: An exploratory study," Journal of Young Pharmacists, vol/issue: 5(2), pp. 5053, 2013.

[28] Ahmad F. A., "Analysis Using Herbal Treatment For Diabetes Mellitus Patients in Clinical Herbal Saintification Hortus Medikus Tawangmangu," Thesis, School of Public Health, University of Indonesia in 2012.

[29] H. Tandi, "The Book of Medicinal Plants Efficacious," Octopus Publishing House, Yogyakarta, 2015.

[30] Kristina L. and Suharmiati, "Rationalization Analysis of Ingredients Remedy Diabetes Mellitus in Laboratory of Research and Development of Traditional Medicine Treatment Services," Buletin Penelitian Sistem Kesehatan, vol/issue: 9(2), pp. 107-112, 2006.

[31] J. Hensarling, "Development and Psychometric Testing of Hensarling's Diabetes Family Support Scale," Texas, Proquest, UMI Dissertation Publishing, 2009.

[32] Chew B. H., et al., "Social Support and Glycemic Control in Adult Patients with Type 2 Diabetes Mellitus," Asia Pacific Journal of Public Health, vol/issue: 20(10), 2011. 